\title{
Miradas sobre Edipo en Tebas Land: de Sófocles a Sergio Blanco
}

Palabras clave: teatro, mito, Edipo, Sófocles, Sergio Blanco, Tebas Land

DOI: $10.4312 /$ ars.9.1.117-128

1

La relación entre mito y mirada se presenta en el teatro erizada de paradojas, cuya más honda raíz es la in-mediatez constitutiva del modo teatral de representación, en el sentido aristotélico de «modo». Bien sabido es que el Estagirita distingue dos y solo dos modos de imitación, o sea, de representación de mundos imaginarios o ficticios, el narrativo y el dramático (Poética, 48a19-30). En varios lugares (García Barrientos, 2004a y 2004b, 17-27 y 111, por ejemplo) he defendido la vigencia de esa distinción, que redefino en términos de modo mediato (la narración) y modo inmediato (la actuación o el teatro): en el primero el mundo ficticio pasa hasta el receptor a través de una instancia mediadora (la voz del narrador, el ojo de la cámara), mientras que en el segundo se presenta -en presencia y en presente- ante los ojos del espectador, directamente, sin mediación alguna. De manera que el cine cae rotundamente del lado de la narración y no de la actuación.

Decir esto, de manera casi axiomática, es tanto como decir que la narración (verbal o visual) es siempre, por su mediación constitutiva, a la fuerza, una mirada sobre el mundo ficticio, sobre el mito; mientras que en la actuación, en el teatro, no hay más mirada que la del propio espectador, pues es el universo imaginario, el mito, el que se pone ante sus ojos, sin que ninguna otra mirada, ninguna mirada de otro, pueda interferir, o sea, intermediar en su representación, constitutivamente inmediata.

Ahora bien, visto del otro lado, el teatro es, hasta etimológicamente, el mirador por excelencia, como ya señalara Ortega y Gasset $(1958,40)$ : «Teatro es por esencia, presencia y potencia visión -espectáculo-, y en cuanto público, somos ante todo espectadores, y la palabra griega $\theta \varepsilon \alpha \tau \rho o v$, teatro, no significa sino eso: miradouro, mirador». Así que no hay lugar donde la mirada sea más decisiva que en el teatro y al mismo tiempo no hay lugar en este «mirador» para las miradas intermediadoras, interpuestas entre la ficción y el destinatario, que son, por contra, las que sostienen 
la narración: la de la cámara, literalmente, en el cine, y, figuradamente, la de la voz narrativa en la literatura.

Sin lugar ni ganas para prolijas precisiones terminológicas, hago solo notar que utilizaré indistintamente «mito» en su sentido más general y extendido ${ }^{1}$, pero también en el aristotélico, específicamente teatral, que suele traducirse por fábula, define el gran filósofo como «la estructuración de los hechos» y considera «el principio y como el alma de la tragedia» (Poética, 50a15 y 50a38-39). Y es que la brevedad de mi exposición aconseja perseguir más la sugerencia que la minucia.

El mito, seguramente el más trágico de todos, al que propongo que dirijamos una mirada reflexiva, necesariamente parcial y limitada, es el de Edipo, en dos manifestaciones teatrales extremas (y no sólo en el tiempo): la canónica e insuperable tragedia de Sófocles Edipo Rey y un drama extraordinario que, estrenado en 2013, es la versión o la visión más reciente que conozco del mito, Tebas Land del dramaturgo franco-uruguayo Sergio Blanco (2013). Mi mirada quiere focalizar precisamente unos pocos aspectos de la distancia entre las dos obras y por tanto, en buena medida, entre los dos autores y las dos épocas, entre la visión trágica y la miopía posmoderna; pero no posdramática.

\section{2}

La importancia de la mirada no puede ser mayor en el interior mismo del mito o la historia de Edipo. Desde el principio (las miradas sobre el niño recién nacido, por ejemplo: la primera de Yocasta, la de Layo, la segunda de Yocasta al entregarlo al servidor-asesino ${ }^{3}$, la del pastor que lo recibe, las de sus padres adoptivos, los reyes de

1 En el sentido, por ejemplo, en que se refiere Nietzsche $(1872, \$ 23,134)$ a «el 'mito', esa imagen sintética del mundo que, en cuanto abreviatura de la apariencia, no puede prescindir del milagro. [...] Pero sin el mito, toda cultura está desposeída de su fuerza natural, sabia y creadora; solo un horizonte constelado de mitos consuma la unidad de una época entera de cultura.»

2 «En la textura de su acción aparece atravesado Edipo rey de tragicidad como ninguna otra obra. En cualquiera de los pasajes de la suerte del héroe en que se repare sorprenderá la unidad de redención y aniquilamiento inherente a lo trágico. Porque no es el aniquilamiento lo que posee entidad trágica, sino la mutación de la redención en aniquilamiento; la tragicidad no estriba en la destrucción del héroe, sino en que el hombre perezca mientras transita por el camino que ha tomado para eludir su destrucción. Esta experiencia cardinal del héroe, refrendada a cada paso que dé, cederá en el último momento ante otra: el camino hacia la destrucción esconde en su término tanto la salvación como la redención.

A diferencia de lo que ocurría aún en Esquilo, en el drama sofócleo los dioses han dejado de comparecer entre los personajes. Pero continúan tomando parte en cuanto sucede. Al héroe no se le concede entera libertad, pero tampoco se le priva enteramente de ella. [...] Lo trágico no es, sin embargo, que la divinidad depare a los hombres cosas terribles, sino que ocurran en virtud de las propias acciones humanas» (Szondi, 1961, 241-242).

3 Así nos la presenta al menos la tragedia (episodio $4^{\circ}$ : vv. 1110-1185): Servidor.- [...] Pero la que está dentro, tu mujer, es la que mejor podría decir cómo fue. 
Corinto, a los que este lo entrega), hasta el fin, de la historia y de la mirada (la ceguera del rey); pasando por todos los momentos clave del mito. Reduciéndonos a las miradas sobre Edipo, pensemos en la segunda de Layo en el cruce de caminos, la de la esfinge, la tercera de Yocasta como salvador de Tebas y como esposo y rey, la terrible cuarta al descubrir que es su hijo, etc. Aunque sea por un momento, consideremos también las miradas del propio Edipo simétricas de estas: a su padre en el camino, a la esfinge, a su madre-esposa, a sus hijos-hermanos ... Se puede sintetizar el mito en ese variopinto cruce de miradas, de la felicidad y la gloria al horror y el vacío. Y es lo que hace en buena parte, si no recuerdo mal, Pasolini en su Edipo, precisamente cinematográfico.

La mirada está ampliamente tematizada también en el texto de Sófocles, sobre todo por su reverso, la ceguera. Desde el episodio $1^{\circ}$ (vv. 216-462), con el enfrentamiento entre el adivino Tiresias y el rey Edipo en la plenitud de su poder, en torno a la paradoja del ciego que lo ve todo y el vidente que no ve nada. Edipo empieza por reconocerla en Tiresias: «Aunque no ves, comprendes, sin embargo, de qué mal es víctima nuestra ciudad» (p. 322). Luego, irritado por la respuesta que él mismo le arranca, le niega que posea la fuerza de la verdad «ya que estás ciego de los oídos, de la mente y de la vista [...] Vives en una noche continua, de manera que ni a mí, ni a ninguno que vea la luz, podrás perjudicar nunca» (p. 325) y lo llama «hechicero, maquinador y charlatán engañoso, que sólo ve en las ganancias y es ciego en su arte» (p. 326). En su demoledora respuesta, Tiresias formula la paradoja (y el destino de Edipo):

Y puesto que me has echado en cara que soy ciego, te digo: aunque tú tienes vista, no ves en qué grado de desgracia te encuentras ni dónde habitas ni con quiénes transcurre tu vida. ¿Acaso conoces de quiénes desciendes? Eres, sin darte cuenta, odioso para los tuyos, tanto para los de allí abajo como para los que están en la tierra, y la maldición que por dos lados te golpea, de tu madre y de tu padre, con paso terrible te arrojará, algún día, de esta tierra, y tú, que ahora ves claramente, entonces estarás en la oscuridad (Sófocles, 327).

Y con mayor concreción añade luego: «Ciego, cuando antes tenía vista, y pobre, en lugar de rico, se trasladará a tierra extraña tanteando el camino con un bastón» (p. 328).

En el estásimo $4^{\text {o }}$ (vv. 1186-1222) el Coro (Antístrofa 2a) exclama: «iAh, hijo de Layo, ojalá, ojalá nunca te hubiera visto!» (p. 358), donde cabe notar la identificación, propia del pensamiento arcaico, entre la realidad y su representación, entre el

Edipo.- ¿Ella te lo entregó?

Servidor.- Sí, en efecto, señor.

Edipo.- ¿Con qué fin?

Servidor.- Para que lo matara.

Edipo.- ¿Habiéndolo engendrado ella, desgraciada?

Servidor.- Por temor a funestos oráculos.

Edipo.-¿A cuáles?

Servidor.- Se decía que él mataría a sus padres (Sófocles, 356). 
desdichado héroe y la mirada sobre su desgracia. Y ya en el éxodo (vv. 1223-1530) se consuma la automutilación de Edipo - «iOh nube de mi oscuridad, que me aíslas, sobrevenida de indecible manera, inflexible e irremediable!» (p. 361)- que lo sume en la soledad más radical. Las dos ideas se suman en la explicación que ofrece del atentado que acaba de cometer contra sí mismo:

Edipo.- [...] No sé con qué ojos, si tuviera vista, hubiera podido mirar a mi padre al llegar al Hades, ni tampoco a mi desventurada madre, porque para ambos he cometido acciones que merecen algo peor que la horca. Pero, además, ¿acaso hubiera sido deseable para mí contemplar el espectáculo que me ofrecen mis hijos, nacidos como nacieron? No por cierto, al menos con mis ojos. [...] Habiéndose mostrado que yo era semejante mancilla, ¿iba yo a mirar a éstos con ojos francos? De ningún modo. Por el contrario, si hubiera un medio de cerrar la fuente de audición de mis oídos, no hubiera vacilado en obstruir mi infortunado cuerpo para estar ciego y sordo (Sófocles, 363).

Pero no es tanto el tema de la mirada lo que quiero resaltar ahora cuanto la posibilidad paradójica de interponer en el teatro miradas que intermedien entre el mito y el espectador. La distinción modal, tal como quedó formulada al principio, no puede ser ni más nítida ni más radical y parece descartarlas de plano. Y así es en sentido estricto. (No hay nada que pueda cambiar el hecho de que en el teatro vemos con nuestros propios ojos y en el cine a través de los ojos de la cámara.) Pero si ascendemos de la raíz al tronco del teatro, la imposible mirada mediadora encuentra por lo menos sucedáneos.

En lo que se refiere a la tragedia griega y a su cima, Edipo Rey, diría que los más decisivos son las figuras del dramaturgo (aunque ausente, responsable de cómo se despliega el mito ante los ojos del público, o sea, del «modo» de presentación) y el coro (en buena medida intermediador, incluso por su posición en la orquesta, entre el público del «théatron»y los actores-personajes de la escena). Démoslo sin más por sentado, con la sola ilustración de lo que sugieren intensamente estas palabras de Nietzsche:

Llegamos ahora a comprender que la escena y la acción, en el fondo y en principio, no estaban concebidas como «visión»; que la única «realidad» es precisamente el coro, que produce él mismo la visión y la expresa con ayuda de toda la simbólica de la danza, del sonido y de la palabra. [...]

Al coro ditirámbico le incumbe, de ahora en adelante, llevar el espíritu de los oyentes a un tal estado de exaltación dionisiaca que, cuando aparece en escena el héroe trágico, no ven, como pudiera creerse, un hombre con el rostro cubierto por una máscara informe, sino más bien una imagen de visión, nacida, por decirlo así, de su propio éxtasis (Nietzsche, [1872] 1964, §8, 59-60). 
Miremos ahora el Edipo de Sergio Blanco, o sea, Tebas Land, que hay que empezar por decir que no es ningún Edipo, o sea, ninguna versión del mito clásico, sino una obra sobre el parricidio y sobre la creación teatral (y quizás sobre la relación oculta entre ambas «acciones»). Escapa así de entrada al justificado reproche que hace George Steiner ([1961] 2001, 237 y ss.) en La muerte de la tragedia a las «actualizaciones» de los mitos clásicos por parte del teatro moderno ${ }^{4}$ y del que solo se salva la Antígona de Anouilh, que «armoniza realmente lo antiguo y lo moderno, iluminándolos a ambos» (p. 241)

«Toda la pieza transcurre durante nuestros días en un escenario de ensayo que representa a su vez la cancha de básquetbol de una prisión» (Blanco, 2014, 29) entre tres personajes: «S, dramaturgo, treinta y nueve años», "Martín Santos, parricida, veintiún años» $y$ «Federico, actor de teatro, veintiún años» (p. 27). Asistimos en el doble espacio al doble diálogo entre el muchacho preso que mató a su padre (Martín) y $S$, el dramaturgo que escribe y dirige una obra sobre el parricidio basada en su caso, por una parte, en la cárcel; y por otra, en la sala de ensayo (que es el mismo espacio desdoblado), entre $\mathrm{S}$ y el actor (Fede) que interpreta en el teatro al parricida. Otra regla del juego es que Martín y Fede, «si bien son dos personajes distintos, deberán sin embargo ser representados durante toda la pieza por un solo y mismo actor» (p. 27). Quizás no solo por eso, S se opone siempre a que los otros dos personajes puedan entrar en contacto directo, sin pasar por él, que es el mediador absoluto entre ambos y también entre todo y el público, como veremos.

La tragedia de Sófocles no puede estar más presente en Tebas Land, pero no en la fábula ni en los caracteres ${ }^{7}$, sino precisamente como una de las más importantes

4 «Lo antiguo no es un guante que el moderno pueda ponerse a voluntad. La mitología del teatro griego era la expresión de una imagen cabal y tradicional de la vida. El poeta podía alcanzar con su auditorio un contacto inmediato de terror o deleite porque poeta y auditorio compartían los mismos hábitos de creencia. [...] Pero hoy el contexto está tan absolutamente modificado que los antiguos mitos resultan caricaturas o acertijos para anticuarios en los escenarios actuales. La estratagema de Eliot es preferible al disparate de Cocteau. Pero ni la una ni el otro dan vida a una pieza de teatro» (p. 241).

5 «Pero se trata de un caso especial. Las circunstancias políticas le daban a la leyenda una sombría vigencia. El conflicto entre la moralidad de la protesta y la moralidad del orden tenía referencias tan directas a la condición del público en la Francia ocupada que Anouilh pudo mantener intacto el significado de la obra de Sófocles. Su traducción de los valores griegos fue literal en el sentido de ser una traducción, un traslado a la angustia del momento» (p. 241).

6 Por donde cito siempre, y no por la edición príncipe (París, Skené, 2013). La obra está dividida (según denominaciones propias del básquetbol) en cuatro «cuartos»o actos, que anoto en números romanos (I-IV), y una «Prórroga» (P) o epílogo, cada uno de los cuales dividido en varios cuadros, que se marcan en el texto por el número correspondiente de asteriscos o estrellas -que podrían recordar las pelotas de básquetbol- y que traduzco a números árabes $(1,2,3 \ldots)$, para localizar así cada cita, además de por el número de página(s), por su lugar en la estructura.

7 Tampoco en ninguno de los otros cuatro elementos de la tragedia según Aristóteles: pensamiento, elocución, melopeya y espectáculo. Por cierto, la mirada está tematizada en la obra de Blanco de 
miradas interpuestas, como auténtico intertexto. Directa y literalmente, pues la obra termina con las primeras palabras del prólogo de la tragedia -«Ciudadanos de Tebas. Hijos míos. Descendencia nueva del antiguo Cadmo. ¿Por qué estáis en actitud de plegaria ante mí, coronados con ramos de suplicantes? [...]» $(\mathrm{P}, 3,123)$ - dichas por el parricida Martín, tal vez leídas, como parece sugerir el cuadro anterior. Aunque en esto como en todo triunfa la ambigüedad o la ambivalencia, consagrada en el texto por la ausencia de acotaciones. Y también indirectamente, como en esas notas de trabajo que S confía al público: «PARRICIDIo, dos puntos, ESTABLECER LÍNEAS DE LECTURA CON Edipo REy, Los hermanos Karamazov y algunos textos de Freud. Un poco más abajo dice consultar el Edipo de Pasolini» (I, 3, 38), o cuando hace leer a Federico, el actor, en uno de los ensayos, un largo texto sobre la Esfinge, supuestamente copiado de Wikipedia, del que cabe destacar, por su implicación en el caso, este pasaje:

La Esfinge habría sido enviada por la diosa Hera para castigar a la ciudad por el amor homosexual que su rey Layo había sentido por el joven Crisipo. Layo no solo había seducido al joven sino que también lo había raptado. Muchos piensan que esta habría sido la primera relación homosexual de la historia $(\mathrm{I}, 4,44)$.

Como se infiere de las citas anteriores, no se trata del único intertexto, aunque sí quizás del más emblemático. Desfilan por el diálogo de la obra otros muchos, literarios como Los hermanos Karamazov, cinematográficos como la película de Pasolini, pero también históricos como la relación de Kafka y Mozart, además de Dostoievski, con sus padres terribles. Se percibe así una de las ambivalencias aludidas, la muy del gusto actual entre ficción y ensayo. La pieza es a la vez un espectáculo fascinante y "un monumental ensayo» -en los dos sentidos- «sobre el teatro actual y sobre lo artístico» (Valiño, 2014, 127), por una parte, y por otra, sobre el parricidio y las relaciones paterno-filiales. Y en ambas líneas temáticas se amalgaman por igual reflexión y ficción, acción y pensamiento. Otras polaridades cargadas de ambigüedad y decisivas en la composición de la obra afectan al juego permanente y muy sofisticado -verdadero encaje de bolillos-entre ficción y realidad, y entre drama y narración.

De las miradas sobre Edipo que se interponen entre el mito arcaico y sus interpretaciones artísticas contemporáneas, quizás la más destacada sea la de Freud y su teoría psicoanalítica, tal como ya lo señaló Steiner [1961] para toda la mitología8.

forma aún más significativa que en la de Sófocles. El espacio disponible no consiente siquiera una consideración paralela a que se hizo antes sobre Edipo Rey, que queda para otra ocasión.

«Uno de los descubrimientos memorables de la inteligencia moderna ha sido que las antiguas fábulas pueden leerse a la luz del psicoanálisis y la antropología. Manipulando los valores míticos es posible extraer de sus rasgos arcaicos sombras de represión psíquica y rituales sangrientos. 
Su presencia en Tebas Land es de la máxima relevancia ${ }^{9}$. La relación de Martín con su padre y con su madre es de libro o de diván de psicoanalista. También, por velada que esté, la de S con su padre -y quizás con su madre, precisamente por el vacío elíptico (¿edípico?) que la cobija. Seguramente en la obra pesa, más que el mito, el complejo de Edipo. Las consecuencias son de alcance. La que más nos importa es el efecto antitrágico de la mirada freudiana interpuesta.

La obra se inserta en el proceso de vulgarización del héroe (y de todo lo demás) ${ }^{10}$, que lleva al extremo el proceso iniciado, si hacemos caso de Nietzsche ([1872] 1964, $\$ 11,71$ ), por Eurípides: «Para él, el hombre de la vida cotidiana salió de las filas de los espectadores e invadió la escena; el espejo, que no reflejaba nunca más que rasgos nobles y fieros, acusó desde entonces esa exactitud servil que reproduce minuciosamente las deformidades de la Naturaleza.» Ante la impermeabilidad de nuestro tiempo a la idea fuerte del destino y a la honda realidad del misterio, la tragedia deriva hacia el caso judicial y hacia el caso patológico ${ }^{11}$.

Se trata de un juego fascinante y que sin duda resulta legítimo dentro de ciertos límites de integridad. En tanto que tienen sus raíces en la memoria primordial del hombre y en tanto que registran, en un código de fantasía, ciertas prácticas muy antiguas y crueles, los mitos griegos pueden documentar con justicia las especulaciones de la psicología y de La rama dorada. Si estas leyendas no hubieran brotado de las fuentes mismas de nuestro ser no podrían ejercer su hechizo perdurable» (Steiner, [1961] 2001, 238).

9 Presidida por el mito y el complejo de Edipo, tanto en el plano argumental como en el reflexivo, que se entrecruzan, la obra tiene tal implicación psicoanalítica, que con razón fue invitado Blanco, para que hablara de ella, a pronunciar la conferencia de clausura del Congreso Internacional de Psicoanálisis celebrado en Montevideo en agosto del 2012. Su ponencia se tituló «Tebas Land: El parricidio como reconocimiento de un fragmento amoroso».

10 Pienso, entre otros muchos aspectos, en cierto efectismo o tremendismo de algunos momentos; por ejemplo, la proyección de las fotos del expediente judicial o el relato mismo del crimen en sus detalles más crudos y siniestros; que, pesar de la pulcritud formal, la contención y el rigor verbal de la obra de Blanco, puede parecer que choca con el extremo "decoro» de la suprema tragedia de Sófocles, pero que no carece de antecedentes en el apolíneo diálogo de la misma. Por ejemplo, en el relato de la automutilación de Edipo por el mensajero (éxodo: vv. 1223-1530): «[...] Una vez que estuvo tendida, la infortunada, en tierra, fue terrible de ver lo que siguió: arrancó los dorados broches de su vestido con los que se adornaba y, alzándolos, se golpeó con ellos las cuencas de los ojos, al tiempo que decía cosas como éstas: que no le verían a él, ni los males que había padecido, ni los horrores que había cometido, sino que estarían en la oscuridad el resto del tiempo para no ver a los que no debía y no conocer a los que deseaba. Haciendo tales imprecaciones una y otra vez -que no una sola-, se iba golpeando los ojos con los broches. Las pupilas ensangrentadas teñían las mejillas y no destilaban gotas chorreantes de sangre, sino que todo se mojaba con una negra lluvia y granizada de sangre» (Sófocles, 359-360).

11 En este sentido, es muy acertada la decisión de Blanco como dramaturgo al no plantear su pieza como una versión o variante moderna de Edipo. De haberlo hecho, al ser tan descomunal la distancia entre el héroe tebano y el demasiado humano Martín Santos, no habría salido incólume de las críticas de Steiner [1961], tanto de las ya citadas como de esta: «Al tratar de darle a la fábula clásica un giro novedoso, la obra contemporánea tiende a destruir su significado. Las desventuras de Edipo en los escenarios de hoy son un alegato contra la frivolidad y la perversión de nuestra fantasía. Gide lo convierte en un hombrecillo petulante que llega a abrigar la extraordinaria idea de que su matrimonio con Yocasta fue un mal porque le retrotrajo a su infancia y de este modo impidió el libre desarrollo de su personalidad (se reconoce en este fárrago el motivo gideano del hijo pródigo). Hoffmannsthal y Cocteau saltan como arpías miopes para apoderarse de esos dos episodios de la 
Como tal conecta de lleno con la mirada de Freud, o sea, con la indagación psicoanalítica, que tiene -y tuvo, por cierto, en efecto- esta provocación expresa en el texto clásico (episodio $3^{\circ}$ : vv. 911-1085), cuando Yocasta tranquiliza así los temores de Edipo: «Tú no sientas temor ante el matrimonio con tu madre, pues muchos son los mortales que antes se unieron también a su madre en sueños. Aquel para quien esto nada supone más fácilmente lleva su vida» (p. 348). Pero es aún mayor la carga de profundidad, tal como advierte Steiner:

Para el judío, hay una maravillosa continuidad entre conocimiento y acción, para el griego, un abismo irónico. La leyenda de Edipo, en la que el sentido irónico de la sinrazón trágica está representado tan horriblemente, le sirvió a ese gran poeta judío que era Freud como emblema de la perspicacia racional y la redención mediante la curación (Steiner, [1961] 2001, 12).

Ambas saturan la obra de Blanco, sobre todo en la relación entre S y Martín, cada vez más comprometida o peligrosa, en el deseo recíproco de descubrir las razones del otro y de redimirlo.

Perola clave de todas las mediaciones, el nudo por el que pasan todas las miradas, es en Tebas Land la figura del personaje denominado de modo expresamente ${ }^{12}$ kafkiano «S», inicial ante todo de Sergio Blanco, pero también de Sófocles, de Sigmund Freud y hasta del actor -Gustavo Saffores- que lo interpretó en la puesta en escena, todavía viva, del estreno en Montevideo, que dirigió el mismo Blanco. El cual, por cierto, si damos algún crédito a sus declaraciones, pensó en un primer momento interpretar al personaje, o sea, interpretarse, para llevar al límite el juego entre realidad y ficción, entre presentación y representación ${ }^{13}$, haciendo pasar con suma eficacia por performativo lo que es en realidad doblemente dramático. También se cruzan en $\mathrm{S}$ los caminos de la ficción y la reflexión, como hemos podido vislumbrar ya, y los aún más decisivos para nuestro propósito de los dos

leyenda que el teatro griego tuvo la reticencia moral y la sabiduría técnica necesarias para dejar intactos: el encuentro entre Edipo y la Esfinge, y la conquista amorosa de Yocasta» (Steiner, [1961] 2001, 239). Me parece altamente recomendable, en este punto, la lectura del excelente relato/ensayo «Vindicación de los labdácidas» de Mercedes Melo Pereira (2013), tanto por las sabrosas variantes (teatrales) del mito que contiene como por sus procedimientos narrativos, paralelos a los que emplea Blanco en la composición de su pieza; por ejemplo, el juego con la ambigüedad ficción/realidad, la metaficcionalidad y sobre todo la multiplicación de las «miradas» interpuestas.

12 "Y por último hay un encuadre en el que dice: PODRÍA LLAMARME S COMO LOS PERSONAJES DE LAS NOVElAS DE KAFKa y ÉL POdRÍA Llamarse Martín» (I, 3, 39). Nótese el juego metateatral, pues es ya $S$ quien confía al público esas supuestas notas donde se supone que habría escrito eso. En ese momento se superponen en él el autor, el director y el actor.

13 «Esta mañana decido que yo mismo voy a estar presente en el escenario. [...] Le cuento que se trata de dar un paso más hacia el principio de performance que propondrá la ejecución del parricidio. Un paso más hacia la des-figuración de la noción de personaje y el fortalecimiento de la persona. Un paso más hacia la desintegración de la escena ficticia para establecer un espacio real. Un paso más que confirmará la imposibilidad de representar el parricidio» (Blanco, 2012, 2). 
modos representativos, dramático y narrativo, tal como apuntamos al principio, lo que da a mi reflexión, necesariamente incompleta, al menos la apariencia de circularidad.

Si bien se mira, confluyen en S las dos formas sucedáneas de mediación que reconocimos en la tragedia griega: la del dramaturgo, hasta el punto de que podemos considerar Tebas Land como un ejemplo de autoficción dramática (cf. García Barrientos, 2014), y la del coro, en su recurrente mediación e interlocución con el público. En efecto, el espectáculo entero hay que entenderlo como la narración de todo el proceso de creación por él mismo, con el concurso de Martín y Federico (las dos caras del mismo actor), del espectáculo, al que asistimos al mismo tiempo que al relato de su génesis. La narración es, como corresponde, la que abre la puerta a todas las demás miradas mediadoras. Pero sin ahogar el carácter profundamente dramático de la obra: no posdramática sino, al contrario, metadramática, o sea, dramática al cuadrado.

Es en ese logro paradójico donde brilla a mi juicio el arte de Sergio Blanco a la altura de los más grandes dramaturgos. Como Pirandello, consigue la mayor ilusión de realidad, no reduciendo sino redoblando la dualidad representativa (real y ficticia) propia del teatro. Y se acerca cuanto es posible hoy, o sea, como dramaturgo de la más avanzada actualidad, al ideal de perfección dramática que sigue residiendo todavía, por pasmoso que deba parecer, en el Edipo Rey de Sófocles: el mito más redondo jamás puesto en escena.

\section{Bibliográfía}

Aristóteles, Poética, ed. trilingüe Valentín García Yebra, Madrid 1974.

Blanco, S., Tebas Land: el parricidio como reconocimiento de un fragmento amoroso. Apuntes de Sergio Blanco. Copia del autor, 2012.

Blanco, S., Tebas Land [2013], La Habana 2014.

García Barrientos, J. L., Teatro y narratividad, Arbor CLXXVII, 699-700, 2004a, pp. 509-524.

García Barrientos, J. L., «Modos» aristotélicos y dramaturgia contemporánea, en: Versus Aristóteles. Ensayos de dramaturgia contemporánea (comp. Moncada, L. M.), México 2004b.

García Barrientos, J. L., Tebas Land de Sergio Blanco y la autoficción teatral, en: Sergio Blanco, Tebas Land, La Habana 2014, pp. 5-16.

Melo Pereira, M., Vindicación de los labdácidas, La Siempreviva 17, 2013, pp. 22-32. 
Nietzsche, F. W., El origen de la tragedia [1872] (trad. Ovejero Mauri, E.), Madrid 1964 ( $4^{\text {a }}$ ed.).

Ortega y Gasset, J., Idea del teatro, Madrid 1958.

Sófocles, Edipo Rey, en: Tragedias (trad. Alamillo, A.), Madrid [1981] 31998, pp. 301-368.

Steiner, G., La muerte de la tragedia [1961] (trad. Revol, E. L.), Barcelona 2001.

Szondi, P., Tentativa sobre lo trágico [1961] (trad. Orduña, J.), Barcelona 1994, pp. 173-314.

Valiño, O., Un espectáculo para mi caja negra, en: Sergio Blanco, Tebas Land, La Habana 2014, pp. 125-128. 


\section{Pogledi na Ojdipa v igri Tebas Land: od Sofokleja do Sergia Blanca}

Ključne besede: gledališče, mit, Ojdip, Sofoklej, Sergio Blanco, Tebas Land

Odnos med mitom in pogledom je še posebej paradoksalen v gledališču, tako starogrškem kot dandanašnjem. Zadeva namreč, po eni strani, ključno potezo načina posnemanja (Aristotel), ki je neposredno vezan na uprizoritev, medtem ko tisti drugi način, pripoved, vedno terja posrednika, torej glas (pripovedovalca) ali pogled (objektiv kamere); toda po drugi strani je gledališče, celo etimološko gledano, gledišče v pravem pomenu besede: fiktivni svet je tam gledalcu postavljen na ogled, neposredno in učinkovito.

Ker je pogled prvenstvenega pomena in v samem središču mita o Ojdipu (od pogleda njegovih staršev, Laja in Jokaste, najprej na novorojenčka, nato na rivalamorilca in obenem rešitelja-kralja-zakonca, pa do nevzdržnega trenutka prepoznanja, iz katerega je edini izhod slepota), v grški tragediji in njenem vrhuncu, Kralju Ojdipu, pogled, kadar ni mogoč, dobi nadomestke, kot sta še posebej zbor in dramatik.

$\mathrm{Na}$ tej osnovi se prispevek ukvarja s pogledi na Ojdipa, ki se prepletajo v eni nedavnih scenskih predelav, v delu Sergia Blanca Tebas Land (2013), v katerem kafkovsko poimenovani lik $» \mathrm{~S} « \mathrm{v}$ perverzni metagledališki igri prevzame vlogo dramatika in zbora, vendar hkrati pooseblja tudi poglede različnih zgodovinskih interpretacij mita, ki se razpenjajo od Sofokleja do Blanca, zlasti pogled Sigmunda Freuda, ki predstavlja tretji zorni kot hermenetvičnega trikotnika in tretjo os lika »S«. 
José Luis García Barrientos

\section{Views of Oedipus in the Play Tebas Land: From Sophocles to Sergio Blanco}

Keywords: theatre, myth, Oedipus, Sophocles, Sergio Blanco, Tebas Land

The relationship between myth and gaze is particularly paradoxical in the theatre, and has been so since the time of Ancient Greek theatre to the present. After all, it pertains, on the one hand, to the most substantial trait of this mode of imitation (Aristotle), which is directly linked to the stage, whereas the second means, narrative, is always mediated by a voice (the narrator) or a gaze (the eye of the camera); and yet on the other hand the theatre is, even etymologically, a theatre par excellence: the fictive world is placed before the eyes of the spectator in a direct and effective manner.

Since the gaze is of paramount importance to the very heart of the myth of Oedipus (from that of his parents, Laius and Jocasta, to the first-born, to the enemy-assassin, and finally to the saviour-king-spouse, and up to the unbearable one of anagnorisis, from which the only solution is blindness), in Greek tragedy, and its summit of Oedipus Rex, the impossible gaze finds substitutes in that of the choir and that of the playwright.

On these bases, this paper examines the views of Oedipus which are intertwined in one of its most recent scenic avatars, namely, in Sergio Blanco's Tebas Land (2013), where the protagonist, called à la Kafka "S", encompasses at the same time the functions of the playwright and of the chorus in a perverse meta-theatrical play, while also embodying the various historical interpretations and views of the myth that exist between Sophocles and Blanco, especially that of Sigmund Freud, the third vertex of the hermeneutical triangle, or the third eye of "S". 